\section{EFFECTS OF COMPETITIVE BLOOD FLOW ON ARTERIAL GRAFT PATENCY AND DIAMETER}

\section{Medium-term postoperative follow-up}

To identify predictors of arterial graft patency, we followed up 30 internal thoracic arterial grafts and 23 right gastroepiploic arterial grafts in situ with patency documented during postoperative angiography. After 24 months of follow-up on average, repeat angiography detected that one internal thoracic artery and two gastroepiploic arteries were anatomically occluded and that the other three gastroepiploic arteries were nonfunctioning. The logistic regression model identified a relationship between graft patency and competitive flow, which was detected as stenosis in the recipient coronary arteries (coefficients, $p<0.05$; model, HosmerLemeshow $\chi^{2}$ statistic 3.59, $p=0.89$ ). The linear regression model demonstrated that changes in graft luminal diameter correlated with competitive flow $(p<0.01)$, smoking history $(p<0.05)$, and type of arterial grafts $(p<0.001)\left(R^{2}=0.40\right.$, adjusted $\left.R^{2}=0.36\right)$. The findings suggest a temporal relationship between competitive flow and prognosis of arterial graft. (J THORAC CaRdiovasC SURG 1996;111:399-407)

\section{Hideki Hashimoto, MD, MPH, ${ }^{\text {a }}$ Takaaki Isshiki, MD, FACC, Yuji Ikari, MD, ${ }^{\text {a }}$ Kazuhiro Hara, MD, ${ }^{\text {a }}$ Fumihiko Saeki, MD, ${ }^{\mathrm{a}}$ Tsutomu Tamura, $\mathrm{MD},{ }^{\mathrm{a}}$ Tetsu Yamaguchi, $\mathrm{MD},{ }^{\mathrm{c}}$ and Hisayoshi Suma, MD, ${ }^{\mathrm{d}}$ Tokyo, Japan}

C oronary artery bypass grafting with the use of arterial conduits is preferable to that with the saphenous vein graft. Several reports have demonstrated that the internal thoracic artery (ITA) has excellent long-term patency and better patient outcomes relative to those with the saphenous vein graft. ${ }^{1}$ The right gastroepiploic artery (GEA) is also currently available and has proved its durability. ${ }^{2,3}$

The indication for use of the arterial graft was initially limited because of concerns regarding diminished runoff when compared with that of the saphenous vein graft. An initial criterion for the use of the ITA involved use of a recipient coronary artery of equal or smaller luminal size. ${ }^{4}$ This criterion was revised after it was demonstrated that arterial grafts adapt to local blood flow demand. ${ }^{5}$

From the Divisions of Cardiology ${ }^{\mathrm{a}}$ and Cardiovascular Surgery, ${ }^{\mathrm{d}}$ Mitsui Memorial Hospital; the Second Department of Inter-

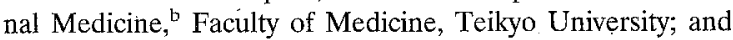
the Third Department of Internal Medicine, ${ }^{c}$ Faculty of Medicine, Toho University, Tokyo, Japan.

Received for publication Jan. 19, 1995.

Accepted for publication May 5, 1995.

Address for reprints: Hideki Hashimoto, MD, MPH, 16 Winter St., \#3, Somerville, MA 02144.

Copyright (C) 1996 by Mosby-Year Book, Inc.

$0022-5223 / 96 \$ 5.00+0 \quad \mathbf{1 2 / 1 / 6 6 2 2 3}$
Several case reports have shown that the ITA responds to changes in flow demand because of the progression of stenosis in the recipient coronary artery. ${ }^{6-8}$ Kitamura and associates ${ }^{9}$ have proved angiographically that the ITA responds rapidly after temporary occlusion of recipient coronary flow during angioplasty. Furthermore, Seki and associates ${ }^{10}$ have quantified the relationship between ITA diameter and recipient coronary artery stenosis.

However, this relationship was identified with use of a cross-sectional design. There is no information regarding changes in graft diameter with time. Moreover, it is a subject of controversy whether the "distal narrowing phenomenon," thought to be a negative adaptation to competitive flow from the recipient coronary artery, ${ }^{11}$ is related to graft patency.

Our current study examines in situ arterial graft patency and diameter changes during the postoperative period with the use of angiography. During a follow-up period of 24 months on average, we identified factors that would affect medium-term arterial graft patency, particularly in relation to stenosis within the recipient coronary artery. An additional purpose of this study was to demonstrate changes in arterial graft diameter over time and assess the effects of the stenosis in the recipient coronary artery on graft luminal diameter. 


\section{Material and methods}

Between January 1983 and December 1992, 938 patients had coronary artery bypass grafting done at our institution. We retrospectively selected patients with patent ITA or GEA grafts in situ documented during postoperative angiography. The initial angiogram (study I) was done within 3 months of the operation. A second angiographic evaluation (study II) was done during a follow-up period of more than 6 months after the operation. Informed consent was obtained before cardiac catheterization in all patients after explanation of potential risks associated with the procedure.

A total of 38 patients were eligible and enrolled in the study. The mean age of the patient population was $57 \pm 8$ years. There were 35 men and 3 women. A total of 30 ITA and 23 GEA grafts were placed. Fifteen patients had both ITA and GEA grafts. Sixteen patients underwent a repeat catheterization because of recurrent chest discomfort. The remaining 22 patients were free of symptoms.

Information regarding the presence of coronary risk factors such as diabetes, hyperlipidemia, and smoking history were obtained from all patients at the time of study I. Data regarding a history of hypertension were not used in the analysis because most patients were treated with vasodilator therapy before the operation; thus these data were believed to be susceptible to misclassification. All patients were taking either antiplatelet or anticoagulant medications. Data were also collected concerning the number of vessels involved, the number of grafts present, and the type of recipient coronary artery noted.

Angiographic procedures were done selectively in the ITA and the GEA with use of a method previously described. ${ }^{12}$ All patients underwent evaluation with the use of nitrate derivatives given before or during the procedure or at both times. In the evaluation of the GEA only, a dose of $0.01 \mu \mathrm{g}$ of intraarterial prostaglandin $\mathrm{E}$ was also administered to prevent vasospasm of the vessel.

During angiographic evaluations, the most severe stenotic region in the recipient coronary artery was measured relative to the adjacent normal coronary diameter from a projection that gave the most severe view of the legion. Similarly, graft diameter ratio at the anastomosis was measured in the most narrowed segment of the graft conduit relative to the adjacent normal graft diameter. This narrowing ratio was measured regardless of type of anastomotic graft narrowing, such as anastomotic stenosis, perianastomotic narrowing, and diffuse distal narrowing. For occluded grafts at study II, the graft diameter was assumed to be zero and the narrowing rate $100 \%$. Evaluation was quantitatively done with a densitometry technique with the Cathex CCIP-310 Heart system, version 3.10 (Cathex Co., Tokyo, Japan).

Significant differences were determined by a Student's unpaired $t$ test for continuous data and a Fisher's exact test for nominal and ordinary data. A $p$ value of $<0.05$ was considered significant.

The relationship between graft patency at study II and parameters obtained at study I was evaluated by the logistic regression model with use of the maximum log likelihood method. Using patency as a dependent variable, simple logistic regression was done for the bivariate analysis. ${ }^{13}$ The multiple regression model by a stepwise method was obtained with use of a log likelihood test. A $p$ value of $<0.05$ was considered significant. The goodness of fit of the model was demonstrated by use of HosmerLemeshow $\chi^{2}$ statistic. $^{14}$

We then attempted to create a linear regression model using the least-square method to explain changes in graft diameters between studies I and II. The dependent variable was defined as graft diameter at study II minus graft diameter at study I. A bivariate analysis using the simple linear regression was done to screen candidate variables collected at study I for a multiple regression model. ${ }^{15}$ The final model was obtained using a partial $\mathrm{F}$ test ${ }^{16}$ accepting a $p$ value of $<0.05$ as significant.

All continuous data were treated as continuous variables. Data regarding graft patency and risk factors were treated as dichotomous indicators. The number of the involved native vessels and the anastomotic regions were treated as score variables. The statistical analysis was done with STATA software, version 3.01 (Computing Resource Center, Santa Monica, Calif.).

\section{Results}

Baseline characteristics. Table I demonstrates patient characteristics and angiographic data obtained during study $\mathrm{I}$. The study was done $21 \pm 19$ days after operation (range 9 to 90 days). Study II was done $24 \pm 9$ months after operation (range 7 to 62 months).

There was no significant difference with respect to coronary risk factors, numbers of involved vessels, and numbers of the anastomoses between patients with ITA grafts and those with GEA grafts. The diameter of GEA grafts was significantly larger than that of ITA grafts, most likely because of the effects of prostaglandin $E$ during the evaluation. The anastomotic narrowing was more severe in the GEA than in the ITA. The most remarkable difference between the ITA and the GEA was with respect to the recipient coronary artery: most ITA grafts were anastomosed to the left anterior descending artery, whereas most GEA grafts were anastomosed to the right coronary artery.

Graft patency. During study II, 1 out of 30 ITAs and 2 out of 23 GEAs were noted to have total occlusion. The patency rate was $97 \%$ in the ITAs and $91 \%$ in the GEAs. Three GEAs were not depicted with selective manual gastroduodenal angiography and opacified retrogradely in native coronary angiography. These GEA grafts were categorized as anatomically patent but physiologically nonfunctioning.

Predictors of graft patency. Six nonfunctioning grafts were compared with the other patent grafts (Table II). There were significant differences regarding the presence of hyperlipidemia, smoking 
Table I. Baseline characteristics

\begin{tabular}{|c|c|c|c|c|}
\hline & $\begin{array}{c}\text { Total } \\
(n=53)\end{array}$ & $\begin{array}{c}I T A \\
(n=30)\end{array}$ & $\begin{array}{c}G E A \\
(n=23) \\
\end{array}$ & $p$ Value \\
\hline Age (yr) & $57 \pm 8$ & $58 \pm 9$ & $55 \pm 6$ & \\
\hline Postoperative angiogram (postop. day) & $21 \pm 19$ & $21 \pm 16$ & $22 \pm 22$ & \\
\hline Stenosis in recipient coronary artery (\%) & $87 \pm 17$ & $88 \pm 17$ & $85 \pm 16$ & \\
\hline Graft diameter $(\mathrm{mm})$ & $2.0 \pm 0.6$ & $1.8 \pm 0.5$ & $2.3 \pm 0.7$ & 0.01 \\
\hline Anastomotic narrowing (\%) & $33 \pm 28$ & $27 \pm 26$ & $42 \pm 28$ & 0.05 \\
\hline Follow-up angiogram (postop. mo) & $24 \pm 9$ & $23 \pm 11$ & $25 \pm 6$ & \\
\hline \multicolumn{5}{|l|}{ Gender } \\
\hline Female & 5 & 3 & 2 & \\
\hline Male & 48 & 27 & 21 & \\
\hline \multicolumn{5}{|l|}{ Smoking history* } \\
\hline Yes & 40 & 24 & 16 & \\
\hline No & 12 & 6 & 6 & \\
\hline \multicolumn{5}{|l|}{ Diabetes* } \\
\hline Yes & 29 & 17 & 12 & \\
\hline No & 23 & 13 & 10 & \\
\hline \multicolumn{5}{|l|}{ Hyperlipidemia* } \\
\hline Yes & 19 & 10 & 9 & \\
\hline No & 33 & 20 & 13 & \\
\hline \multicolumn{5}{|l|}{ Severity of coronary disease* } \\
\hline 1 Vessel & 2 & 1 & 1 & \\
\hline 2 Vessels & 12 & 8 & 4 & \\
\hline 3 Vessels & 37 & 20 & 17 & \\
\hline 3 plus LMT & 1 & 1 & 0 & \\
\hline \multicolumn{5}{|l|}{ No. of bypass grafts* } \\
\hline 1 & 2 & 1 & 1 & \\
\hline 2 & 12 & 7 & 5 & \\
\hline 3 & 17 & 11 & 6 & \\
\hline 4 & 21 & 11 & 10 & \\
\hline \multicolumn{5}{|l|}{ Recipient coronary artery } \\
\hline LAD & & 28 & 3 & $<0.01$ \\
\hline $\mathrm{Cx}$ & & 2 & 3 & \\
\hline $\mathrm{RCA}$ & & 0 & 17 & \\
\hline
\end{tabular}

$L M T$, Left main trunk; $L A D$, left anterior descending artery; $C x$, left circumflex artery; $R C A$, right coronary artery.

* One missing in the GEA group.

history, and the graft diameter at study I $(p=0.05)$. Anastomotic narrowing was marginally significant $(p=0.07)$. Stenosis in the recipient coronary artery was significantly more severe in functioning grafts relative to that in nonfunctioning ones $(p<0.01)$.

The results of bivariate analysis are shown in Table III. The degree of recipient coronary artery stenosis was the only significant factor found to be associated with graft patency $(p<0.01)$. The type of arterial graft used was only marginally significant $(p=0.07)$. The first multiple logistic regression model was built using three parameters: age, native coronary stenosis, and anastomotic narrowing. Although the type of arterial graft used had a $p$ value of less than 0.25 , only one ITA was occluded and the distribution of the parameter was highly skewed, and thus it was not included in the model. The final model included the latter two parameters (Table
IV). Of these, only the degree of recipient coronary artery stenosis had a $p$ value of less than 0.05 . Any interaction terms between parameters were not included in the model significantly. The final model had a Hosmer-Lemeshow statistic equal to 3.59 $(p=0.89)$, which showed fair goodness of fit of the model.

The same procedure was repeated after the three anatomically patent but nonfunctioning grafts were recategorized as patent. A bivariate analysis demonstrated that no parameter had a $p$ value of less than 0.25 with the exception of the degree of recipient coronary artery stenosis $(p=0.12)$. A multiple regression model was not available because no significant $p$ values were obtained from the parameters examined.

Further analysis was done focusing on the distribution of the stenosis in the recipient coronary 
Table II. Comparison between nonfunctioning and functioning grafts

\begin{tabular}{|c|c|c|c|}
\hline & $\begin{array}{l}\text { Nonfunctioning } \\
\quad(n=6)\end{array}$ & $\begin{array}{l}\text { Functioning } \\
(n=46)^{*}\end{array}$ & p Value \\
\hline Age (yr) & $53 \pm 7$ & $58 \pm 7$ & \\
\hline Postoperative angiogram (postop. day) & $29 \pm 17$ & $20 \pm 30$ & 0.05 \\
\hline Stenosis in recipient coronary artery (\%) & $66 \pm 28$ & $89 \pm 14$ & 0.01 \\
\hline Graft diameter $(\mathrm{mm})$ & $1.7 \pm 0.3$ & $2.0 \pm 0.6$ & 0.05 \\
\hline Anastomotic narrowing (\%) & $52 \pm 24$ & $30 \pm 26$ & \\
\hline Follow-up angiogram (postop. mo) & $26 \pm 4$ & $24 \pm 10$ & 0.05 \\
\hline \multicolumn{4}{|l|}{ Gender } \\
\hline Female & 0 & 5 & \\
\hline Male & 6 & 41 & \\
\hline \multicolumn{4}{|l|}{ Smoking history } \\
\hline Yes & 5 & 35 & 0.05 \\
\hline No & 1 & 11 & \\
\hline \multicolumn{4}{|l|}{ Diabetes } \\
\hline Yes & 3 & 26 & \\
\hline No & 3 & 20 & \\
\hline \multicolumn{4}{|l|}{ Hyperlipidemia } \\
\hline Yes & 2 & 17 & 0.05 \\
\hline No & 4 & 29 & \\
\hline \multicolumn{4}{|l|}{ Severity of coronary disease } \\
\hline 1 Vessel & 0 & 2 & \\
\hline 2 Vessels & 2 & 10 & \\
\hline 3 Vessels & 4 & 33 & \\
\hline 3 plus LMT & 0 & 1 & \\
\hline \multicolumn{4}{|l|}{ No. of bypass grafts } \\
\hline 1 & 1 & 1 & \\
\hline 2 & 1 & 11 & \\
\hline 3 & 2 & 15 & \\
\hline 4 & 2 & 19 & \\
\hline \multicolumn{4}{|l|}{ Recipient coronary artery } \\
\hline $\mathrm{LAD}$ & 0 & 33 & \\
\hline $\mathrm{Cx}$ & 2 & 2 & \\
\hline $\mathrm{RCA}$ & 4 & 11 & \\
\hline
\end{tabular}

$L M T$, Left main trunk; $L A D$, left anterior descending artery; $C x$, left circumflex artery; $R C A$, right coronary artery.

*One missing.

artery and its relationship with graft patency. As Fig. 1 shows, four out of six nonfunctioning grafts has less than $60 \%$ stenosis in the recipient vessel. All functioning grafts had more than $60 \%$ stenosis in the recipient artery.

Changes in graft diameter. The change in graft diameter between studies I and II was calculated as defined earlier in this paper. Eighteen grafts demonstrated a reduction in luminal diameter, five demonstrated no change, and the other 30 demonstrated an increase in diameter. Diameter change less than $-0.8 \mathrm{~mm}$ was a threshold to accurately predict graft patency in all but one graft (Fig. 2).

Bivariate analysis using a simple regression model demonstrated that age, gender, smoking history, graft diameter, anastomotic narrowing, type of arterial graft used, and stenosis of the recipient coronary artery had $p$ values of less than 0.25 (Table V).
With the exception of gender, all parameters were included in the first multiple regression model. Gender was excluded from the model because it was correlated highly with the other parameters and might result in multicolinearity problems. The final model included the following parameters with statistical significance: stenosis in the recipient coronary artery, smoking history, and type of arterial graft used (Table VI). This model had a coefficient of determination $\left(\mathrm{R}^{2}\right)$ of 0.40 (adjusted $\mathrm{R}^{2}=0.37$ ). No interaction terms were significantly included.

\section{Discussion}

In this study, we observed excellent long-term patency of the arterial bypass conduits. The result is consistent with those of previous reports. Our logistic regression model demonstrated that anastomotic graft narrowing and the degree of the recipient 


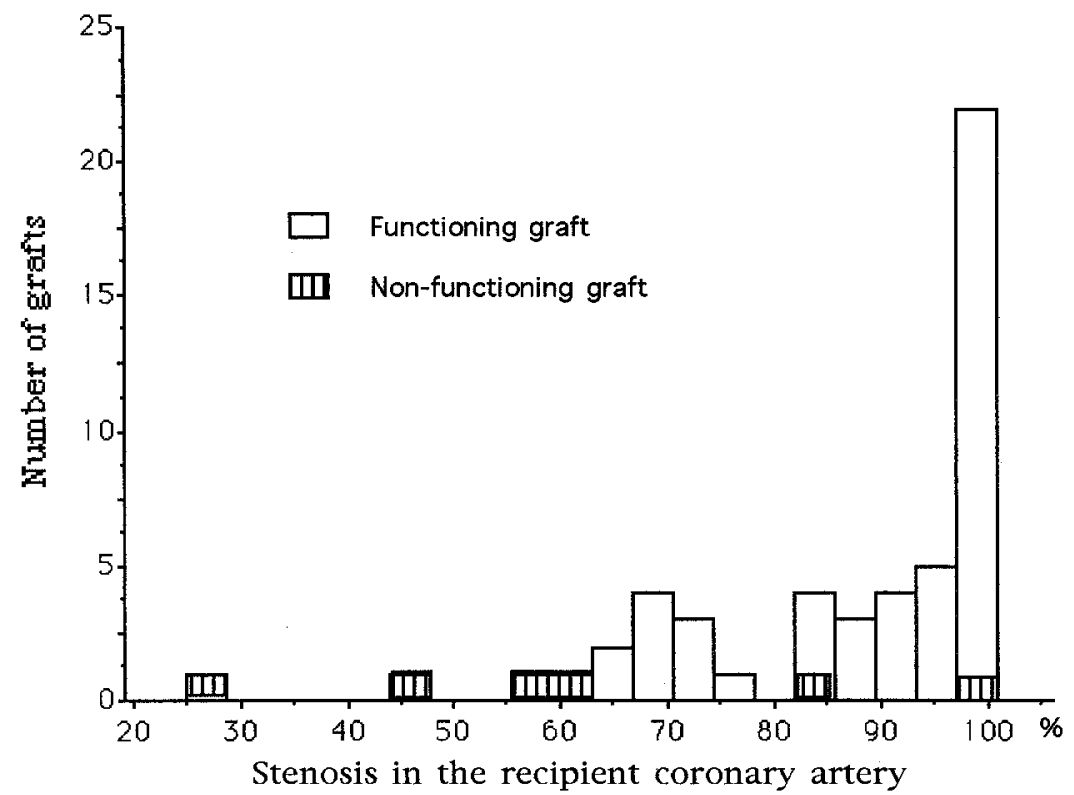

Fig. 1. Distribution of stenosis in recipient coronary artery.

Table III. Bivariate analysis of graft patency

\begin{tabular}{|c|c|c|c|c|}
\hline & Odds ratio & & & p Value \\
\hline Age & 0.90 & 0.8 & 1.04 & 0.16 \\
\hline Stenosis in recipient coronary artery & 0.91 & 0.86 & 0.98 & 0.007 \\
\hline Graft diameter & 0.45 & 0.08 & 2.43 & 0.36 \\
\hline Anastomotic narrowing & 1.02 & 0.98 & 1.05 & 0.24 \\
\hline Follow-up angiogram & 1.03 & 0.94 & 1.12 & 0.57 \\
\hline Gender** & - & - & - & - \\
\hline Smoking history (no $=0$, yes $=1$ ) & 1.57 & 0.69 & 14.92 & 0.39 \\
\hline Diabetes (no $=0$, yes $=1$ ) & 0.76 & 0.14 & 4.22 & 0.76 \\
\hline Hyperlipidemia (no $=0$, yes $=1$ ) & 0.85 & 0.14 & 5.15 & 0.86 \\
\hline Severity of coronary disease & 0.86 & 0.2 & 3.64 & 0.84 \\
\hline Type of arterial graft $(\mathrm{ITA}=0, \mathrm{GEA}=1)$ & 8.05 & 0.87 & 74.6 & 0.07 \\
\hline
\end{tabular}

$C I$, Confidence interval.

* Logistic model could not be constructed because all patients with occluded grafts were male.

coronary artery stenosis predicted arterial graft patency. Stenosis more than $60 \%$ in the recipient vessel was a dividing line between functioning and nonfunctioning grafts. The graft diameter was reduced more than $0.8 \mathrm{~mm}$ in occluded grafts, and changes in graft diameter were predicted in the regression model by smoking history, the type of an arterial graft, and the degree of stenosis in the recipient coronary artery.

It is known that inappropriate anastomosis and technical insufficiency during dissection of the graft conduit can result in narrowing and obstruction of the arterial graft. ${ }^{17}$ Because our study included only patent grafts during the early postoperative evalua- tion, the impact of these technical issues may be underestimated.

However, the graft narrowing rate at the GEA anastomosis in study I may need some consideration. The operative technique used, of which details were reported previously, ${ }^{18}$ has been broadly accepted. Among five nonfunctioning GEA grafts, four showed less than 30\% anastomotic narrowing and had no technical problems. Narrowing was unlikely to have been related to suture placement because it was measured in the conduit rather than the heal or the toe of the anastomosis. Because we used prostaglandin $\mathrm{E}$ during the evaluation of the GEA to obtain maximum vascular relaxation, this 


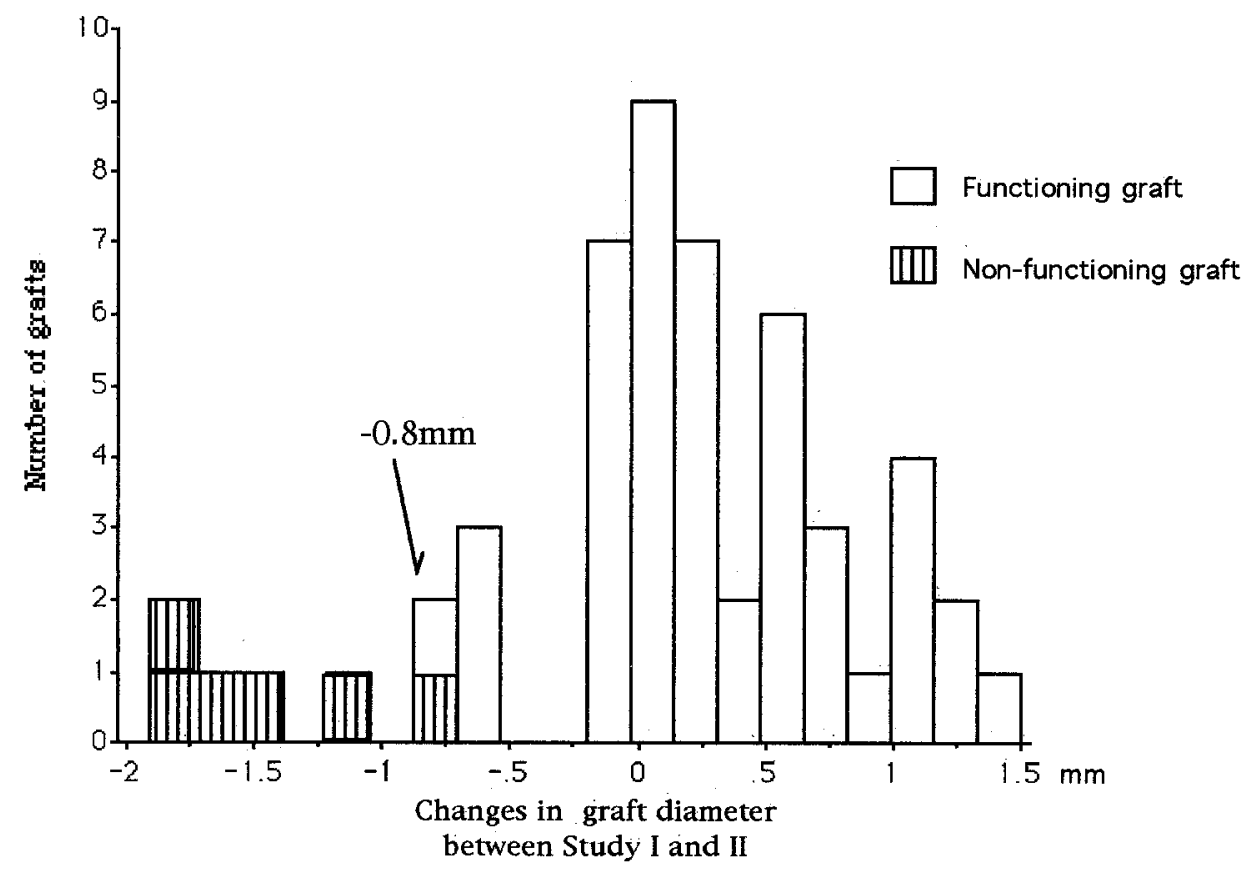

Fig. 2. Distribution of changes in graft diameter between study I and II.

Table IV. Multiple logistic regression model of graft patency

\begin{tabular}{lccc}
\hline & Odds ratio & $95 \%$ CI & $p$ Value \\
\hline $\begin{array}{l}\text { Stenosis in recipient coro- } \\
\text { nary artery }\end{array}$ & 0.9 & $0.84-0.98$ & 0.01 \\
Anastomotic narrowing & 1.02 & $0.98-1.04$ & 0.18 \\
\hline
\end{tabular}

$C I$, Confidence interval. Log likelihood $=-8.677$. Hosmer-Lemeshow $\chi^{2}$ $($ degree of freedom $=8)=3.59 . p$ Value $=0.89$.

may have led to a larger reference graft diameter, which may bias the narrowing rate higher. Another possibility is that competitive flow from the recipient artery precludes opacification by the contrast material of the dilated graft, which may result in overestimation of the narrowing rate by densitometry measure.

Our data suggest that $60 \%$ stenosis in the recipient coronary artery could be a watershed for graft patency. Of two nonfunctioning grafts that had more than $60 \%$ stenosis in the recipient vessel, one was subjected to balloon angioplasty of the recipient artery region during a follow-up period. Thus competitive flow could also affect the patency of this graft.

Although controversy exists, previous studies have examined effects of competitive flow between the graft conduit and the recipient coronary artery with respect to the arterial graft patency.
Urschel and colleagues ${ }^{19}$ concluded from their results of intraoperative angioplasty that competitive flow may not affect graft patency. The study, which examined 42 grafts, was descriptive in design and had no control group. Cosgrove and associates ${ }^{20}$ compared 13 ITAs that were anastomosed to recipient coronary arteries with less than $50 \%$ stenosis with 27 ITAs that were anastomosed to recipient vessels with more severe stenosis. The authors reported that there was no difference between these two groups in terms of graft patency. In our study, patent grafts were anastomosed to recipient arteries with an average stenosis of $89 \%$, whereas occluded grafts were anastomosed to arteries with an average of $66 \%$ stenosis. Because our data showed that $60 \%$ stenosis might be a threshold, $50 \%$ stenosis may be too low as a criterion to give a change in local coronary flow and may underestimate the effect of different competitive flow status on graft patency:

However, whether the anatomically occluded grafts and the nonfunctioning grafts should be viewed in a similar manner is still unclear. Seki and colleagues ${ }^{10}$ have demonstrated the quantitative relationship between the recipient coronary stenosis and graft diameter in postoperative angiographic evaluation. In the analysis; they included patients with occluded ITAs because the relationship be- 
Table V. Bivariate analysis of graft diameter change*

\begin{tabular}{|c|c|c|c|c|}
\hline & Coefficient & & & $p$ Value \\
\hline Age & $0.029^{\circ}$ & 0.023 & 0.055 & $0.03 \dagger$ \\
\hline Gender $($ male $=0$, female $=1)$ & 0.635 & -0.066 & 1.336 & 0.08 \\
\hline Follow-up angiogram & 0.003 & -0.02 & 0.027 & 0.76 \\
\hline Stenosis in recipient coronary artery & 0.019 & 0.007 & 0.03 & $<0.01 \dagger$ \\
\hline Anastomotic narrowing & -0.009 & -0.016 & -0.001 & $0.02 \dagger$ \\
\hline Graft diameter & -0.364 & -0.68 & -0.049 & $0.02 \dagger$ \\
\hline Severity of coronary disease & 0.167 & -0.21 & 0.544 & 0.38 \\
\hline No. of bypass grafts & 0.097 & -0.145 & 0.339 & 0.42 \\
\hline Type of arterial graft $(\mathrm{ITA}=0, \mathrm{GEA}=1)$ & -0.665 & -1.048 & -0.281 & $<0.01 \uparrow$ \\
\hline Smoking history (no $=0$, yes $=1$ ) & -0.4 & -0.898 & 0.0979 & $0.11 \dagger$ \\
\hline Diabetes $($ no $=0$, yes $=1)$ & -0.107 & -0.539 & 0.325 & 0.62 \\
\hline Hyperlipidemia $($ no $=0$, yes $=1$ ) & 0.012 & -0.434 & 0.459 & 0.95 \\
\hline
\end{tabular}

${ }^{*}$ Graft diameter change was defined as graft diameter at situdy II minus graft diameter at study I.

†Variables used for multivariable analysis.

$C l$, Confidence interval.

Table VI. Multiple linear regression model of graft diameter change

\begin{tabular}{|c|c|c|c|c|}
\hline & Coefficient & & & $p$ Value \\
\hline Stenosis in recipient coronary artery & 0.0174 & 0.007 & 0.076 & 0.001 \\
\hline Type of arterial graft $(\mathrm{ITA}=0, \mathrm{GEA}=1)$ & -0.649 & -0.996 & -0.303 & 0.001 \\
\hline Smoking history $($ no $=0$, yes $=1$ ) & -0.48 & -0.885 & -0.076 & 0.02 \\
\hline
\end{tabular}

Coefficient of determinant $=0.40$ (Adjusted $=0.37)$. CI, Confidence interval.

tween the distal narrowing phenomenon and the occlusion of the ITA graft was uncertain. They assumed the graft narrowing to be benign if intraoperative damage to the graft could be excluded. However, it is often difficult to differentiate between anatomic occlusion and physiologic occlusion solely with angiography. Moreover, we found the effects of competitive flow remained some explanation for graft patency even after anatomically patent but nonfunctioning grafts were recategorized as patent. Although the result after recategorization was not statistically significant, this may be because of small numbers of graft occlusion and less statistical power. Assuming a conservative approach ${ }^{21}$ we believe that the degree of competitive flow should be a consideration when an arterial graft bypass is chosen. We also consider the prognosis of graft narrowing as uncertain and perform revascularization even in nonfunctioning grafts.

Whether the GEA is more likely to be susceptible to competitive flow than the ITA is difficult to determine because only one ITA was occluded in our series. However, the type of arterial graft may affect graft diameter change. A previous in vitro study has shown that the GEA is more susceptible to vasospasm than the ITA. ${ }^{23}$ We have found (unpublished data) that there is a difference in blood pressure between the GEA and the ITA by 10 to
$15 \mathrm{~mm} \mathrm{Hg}$ when sequential measurements are obtained. The lower pressure in the GEA might affect graft patency and diameter change because the vessel might be more susceptible to competitive flow. However, more data are required before circulatory differences between the ITA and the GEA are distinguished.

Limitations. Our study has several limitations. First, the sample size is small. Furthermore, the study is not prospective or randomized, and thus our study is not free from sampling bias. However, our findings were consistent with those of previous studies with respect to competitive flow and graft diameter. Thus the reliability of our results may be supported.

Second, our assumption regarding the relationship between native coronary stenosis and competitive flow status has not been empirically proved. Although previous studies have also used this assumption, it is technically difficult to measure in vivo coronary flow. Recently, a Doppler-tipped angioplasty guide wire has been available to detect translesional pressure gradients and flow changes. ${ }^{24}$ This technique will help clarify the validity of the hypothesis.

Third, because the ITA was mostly used with the left anterior descending artery whereas the GEA was mainly used with the right coronary artery, a different pattern of graft use precludes analysis of 
the relationship between graft patency and types of the recipient vessels. In our study sample, we had only one occluded ITA, which was anastomosed to the circumflex coronary artery. The graft was the only ITA that had less than $60 \%$ stenosis in the recipient artery. We did not have enough data to specify the main cause for the occlusion of this graft. Because all the ITAs that were anastomosed to the left anterior descending coronary artery were functioning and had more than $60 \%$ stenosis in the recipient vessel, we cannot identify the specific relationship between patency of the ITAs and the stenosis in the left anterior descending artery as Seki and colleagues ${ }^{10}$ were able to clarify. Huddleston and associates ${ }^{25}$ reported that patency of the ITA is affected by type of recipient coronary artery and that graft patency in the left anterior descending artery is significantly better than that in other coronary arteries. As for the GEA, a recent report by Suma and associates $^{26}$ also showed slightly better patency of the GEA that was anastomosed exclusively to the left anterior descending artery than was shown in their previous report of GEAs largely anastomosed to the right coronary artery. Thus the observed difference in patency between the ITA and the GEA might be attributed to different patterns of recipient vessel selection. Further research is required to detect how different recipient coronary arteries affect the patency of arterial grafts.

In conclusion, series of angiograms revealed that, during a medium-term postoperative follow-up, stenosis in the recipient coronary artery affects arterial graft patency, most likely because of secondary effects of competitive flow. Furthermore, recipient coronary stenosis is also correlated with changes in graft luminal diameter with time, which might suggest the relationship between graft narrowing and prognosis of the graft.

\section{REFERENCES}

1. Lytle BW, Loop FD, Cosgrove DM, Ratliff NB, Easley K, Taylor C. Long-term (5 to 12 years) serial studies of internal mammary artery and saphenous vein coronary bypass grafts. J THORAC CARDIOvasC SURG 1985;89:248-58.

2. Suma H, Fukumoto $H$, Takeuchi A. Coronary artery bypass grafting by utilizing in situ right gastroepiploic artery: basic study and clinical application. Ann Thorac Surg 1987;44:394-7.

3. Suma H, Wanibuchi $Y$, Terada Y, Fukuda S, Takayama T, Furuta S. The right gastroepiploic artery graft: clinical and angiographic midterm re- sults in 200 patients. J Thorac Cardiovasc Surg 1993;105:615-23.

4. Green GE. Technique of internal mammary-coronary artery anastomosis. J THORAC CARDIOvaSC SURG 1979;78:455-61.

5. Singh RN, Beg RA, Kay EB. Physiological adaptability: the secret of success of the internal mammary artery grafts. Ann Thorac Surg 1986;41:247-50.

6. Dincer B, Barner HB. The "occluded" internal mammary artery graft: restoration of patency after apparent occlusion associated with progression of coronary disease. J THORAC CARDIOVASC SURG 1983;85:318-20.

7. Singh RN, Sosa JA. Internal mammary artery: a "live" conduit for coronary bypass. J THORAC CARDIOvasc SURG 1984;87:936-8.

8. Suma H. Internal thoracic artery and competitive flow. J Thorac Cardiovasc Surg 1991;102:639-40.

9. Kitamura S, Kawachi K, Seki T, Sawabata N, Morita R, Kawata T. Angiographic demonstration of no-flow anatomical patency of internal thoraciccoronary artery bypass grafts. Ann Thorac Surg 1992;52:156-9.

10. Seki T, Kitamura S, Kawachi K, et al. A quantitative study of postoperative luminal narrowing of the internal thoracic artery graft in coronary artery bypass surgery. J Thorac CARDIOVASC SuRg 1992;104: 1532-8.

11. Geha AS, Baue AE. Early and late results of coronary revascularization with saphenous vein and internal mammary artery grafts. Am J Surg 1979; 137:456-62.

12. Isshiki $T$, Yamaguchi $T$, Nakamura $M$, et al. Postoperative angiographic evaluation of gastroepiploic artery grafts: technical considerations and short-term patency. Cathet Cardiovasc Diagn 1990;21:233-8.

13. Mickey J, Greenland S. A study of the impact of confounder selection criteria on effect estimation. Am J Epidemiol 1989;129:125-37.

14. Hosmer DW, Lemeshow S. Applied logistic regression. New York: John Wiley \& Sons, 1989:31-4, 140-5.

15. Bendel RB, Afifi AA. Comparison of stopping rules in forward regression. J Am Stat Assoc 1977;72:46-53.

16. Kleinbaum DG, Kupper LL, Muller KE. Applied regression analysis and other multivariable methods. 2nd ed. Belmont, Calif.: Duxbury Press, 1988:131-6.

17. Mills NL, Ochsner JL. Technique of internal mammary-to-coronary artery bypass. Ann Thorac Surg 1974;17:237-46.

18. Suma $\mathbf{H}$. The right gastroepiploic artery graft. In: Grooters RK, Nishida $\mathrm{H}$, eds. Alternative bypass conduits and methods for surgical coronary revascularization. Armonk, New York: Futura, 1994:4771.

19. Urschel HC, Razzuk MA, Miller E, Chung SY. Op- 
erative transluminal balloon angioplasty. J THORAC Cardiovasc Surg 1990;99:581-9.

20. Cosgrove DM, Loop FD, Saunders CL, Lytle BW, Kramer JR. Should coronary arteries with less than fifty percent stenosis be bypassed? J THORAC CARDIOVASC SURG 1981;82:520-30.

21. Siebenmann R, Egloff L, Hirzel H, Rothlin M, Studer M, Tartini R. The internal mammary artery "string phenomenon." Eur J Cardiothorac Surg 1993;7:235-8.

22. Ochiai M, Ohno N, Taguchi J, et al. Responses of human gastroepiploic arteries to internal mammary arteries and saphenous veins. J THORAC CARDIOvasC SURG 1992;104:453-8.

23. Yang Z, Siebenmann R, Studer M, Egloff L, Luscher
TF. Similar endothelium-dependent relaxation, but enhanced contractility, of the right gastroepiploic artery as compared with the internal mammary artery. J Thorac Cardiovasc Surg 1992;104:459-64.

24. Donohue TJ, Kern MJ, Aguirre FV, et al. Assessing the hemodynamic significance of coronary artery stenosis: analysis of translesional pressure-flow velocity relations in patients. J Am Coll Cardiol 1993;22: 449-58.

25. Huddleston CB, Stoney WS, Alford WC, et al. Internal mammary artery grafts: technical factors influencing patency. Ann Thorac Surg 1986;42:543-9.

26. Suma H, Amano A, Fukuda S, et al. Gastroepiploic artery graft for anterior descending coronary artery bypass. Ann Thorac Surg 1994;57:925-7.

\section{Bound volumes available to subscribers}

Bound volumes of The Journal of THORACIC AND CARDIOvascular SURGERY are available to subscribers (only) for the 1996 issues from the Publisher, at a cost of $\$ 100.50$ for domestic, $\$ 128.94$ for Canadian, and $\$ 120.50$ for international subscribers for Vol. 111 (January-June) and Vol. 112 (July-December). Shipping charges are included. Each bound volume contains a subject and author index and all advertising is removed. Copies are shipped within 60 days after publication of the last issue of the volume. The binding is durable buckram with the Journal name, volume number, and year stamped in gold on the spine. Payment must accompany all orders. Contact Mosby-Year Book, Inc., Subscription Services, 11830 Westline Industrial Drive, St. Louis, Missouri 63146-3318, USA; phone 800-453-4351 or 314-453-4351.

Subscriptions must be in force to qualify. Bound volumes are not available in place of a regular JourNaL subscription. 